\title{
Breaking the seals: Efficient mRNA detection from human archival paraffin-embedded tissue
}

\author{
ROMANA ILLIG, ${ }^{1}$ HELGA FRITSCH, ${ }^{1}$ and CHRISTOPH SCHWARZER ${ }^{2}$ \\ ${ }^{1}$ Division of Clinical and Functional Anatomy, Innsbruck Medical University, 6020 Innsbruck, Austria \\ ${ }^{2}$ Department of Pharmacology, Innsbruck Medical University, 6020 Innsbruck, Austria
}

\begin{abstract}
During our study on HOXA13, HOXD12, and HOXD13 mRNA expression in human adult and embryonic tissues, we were confronted with the fact that, within our specimen collection, as in other University Departments in Europe, $<20 \%$ of all samples yielded reliable labeling, while most samples were resistant to hybridization by standard protocols due to over-fixation. Fixation is essential for specimen stability, especially when samples are stored at room temperature and used for histology, and people tend to be more worried about under- than over-fixation. On the other hand fixation inhibits penetration by the probe and may also trap mRNA within ribosomes. Therefore, we developed a nonradioactive in situ hybridization technique, which allows detection of mRNA expressed on low levels from a variety of differentially fixed tissues while maintaining tissue integrity. This was achieved by improving target retrieval and probe detection. In contrast with others, our method allows reliable staining from tissues that are fixed in paraformaldehyde from four hours to over one week, and archived samples that were stored at room temperature for several years (17-19 $\mathrm{yr}$ in some cases) and exceeds detection limits of purely fluorescent methods. Our protocol is highly suitable for detecting CDX-2 mRNA in carcinoma specimens, but especially designed to investigate mRNAs in nonpathological adult and embryonic tissues. Due to the use of standardized probes, we do not expect problems in detecting other mRNAs expressed in suitable amounts.
\end{abstract}

Keywords: target retrieval; human ontogeny; hindgut; embryonic development; chromogenic mRNA detection; tumor

\section{INTRODUCTION}

Homeobox $(H O X)$ genes are a family of highly conserved transcription factors that are expressed during embryonic development as well as in adult tissues (Lewis 1978; Gehring 1987). Their function as "master-regulatory genes" of the temporal and spatial regulation of patterning during embryonic development is well accepted (Duboule 1994; Krumlauf 1994; Samuel and Naora 2005). Malfunctioning and dysregulation of these genes during development lead to innate deformities and malformations (Dolle et al. 1993a; Mark et al. 1997; Zakany et al. 1997). Dysregulation of $H O X$ genes in adult tissue has been directly linked with cancer and tumorigenesis (Warot et al. 1997; Yahagi et al. 2004; Grier et al. 2005). Our understanding of the role of $H O X$ genes has mostly relied on animal models and,

Reprint requests to: Christoph Schwarzer, Department of Pharmacology, Innsbruck Medical University, Peter-Mayr-Strasse 1a, A-6020 Innsbruck, Austria; e-mail: Schwarzer.Christoph@i-med.ac.at; fax: +43-512-9003-73200.

Article published online ahead of print. Article and publication date are at http://www.rnajournal.org/cgi/doi/10.1261/rna.1278109. therefore, remains limited in normal and diseased human tissues (Johnson 1914; Kluth et al. 1995). In order to establish a relationship between $H O X$ gene dysregulation and tissue pathogenesis, it would be useful to analyze formalin-fixed and paraffin-embedded (FFPE) samples that are stored in anatomy, histology, embryology, and pathology departments worldwide. These collections of human tissues are extremely valuable, as they might help unravel developmental and pathological pathways. The lack of a standard procedure for tissue fixation, in clinical and anatomical institutions, is the main drawback for accurate gene-expression analysis by in situ hybridization. Although these fixation techniques have allowed histological analysis and diagnosis, they have hindered the localization of transcripts within tissues. Previous work performed on an embryonic tissue collection in the Department of Anatomy of Innsbruck Medical University demonstrated that $<20 \%$ of all samples had been fixed in a manner that allowed in situ hybridization analysis by standard procedures (Breitschopf et al. 1992; Blumer et al. 2006). A fluorescent method with improved target retrieval, designed for the detection of nascent RNA in nuclei of cancer samples 
published by Capodieci et al. (2005), does not allow estimation of expression levels, which is crucial in developmental studies. In addition, the authors state that they observed only $50 \%$ fewer transcription sites when they used fewer than eight labeled oligonucleotides. In line with this, we found that the use of fluorescence-labeled DNA oligomers did not result in sufficient sensitivity to detect HOX mRNA in all embryonic tissue displaying positive immunolabeling. Therefore, we optimized a chromogenic in situ hybridization protocol allowing analysis of mRNAs expressed on low levels in all types of FFPE tissues, regardless of the method of fixation or tissue origin.

We investigated HOXA13, HOXD12, and HOXD13 mRNAs in the abdomen, pelvic floor, and limbs of embryonal tissues and adult rectum, and CDX-2 mRNA in adenocarcinoma and embryonal specimens. Our method drastically increased the percentage of suitable specimens from $<20 \%$ to $100 \%$ of embryonic and adult human tissues in our collection.

\section{RESULTS}

Optimization of the in situ hybridization protocol was performed on three differently fixed $(4 \mathrm{~h}$, short fixed; $3 \mathrm{~d}$, medium fixed; and $7 \mathrm{~d}$, long fixed in $4 \%$ paraformaldehyde) specimens obtained from one adult human rectum. As depicted in Figure 1, the protocol given below yielded reliable staining for three HOX mRNAs on all specimens investigated. The staining pattern is distinct for the three probes, but consistent across fixation times (Fig. 1). HOXA13-positive cells were observed in all rectal layers with the exception of the mesorectum. The highest densities of positive cells were displayed in the laminae propria and muscularis mucosae (Fig. 1a,d,g) and the tunica muscularis. HOXD12 mRNA-positive cells were generally rare. Some were observed in the laminae propria and muscularis mucosae (Fig. 1b,e,h). HOXD12-expressing cells were found neither in the tunica muscularis nor in the mesorectum (data not shown). HOXD13 mRNA signal was observed in scattered cells of the tunicae mucosa and muscularis (Fig. 1c,f,i) and the mesorectum. The specificity of the staining was controlled by immunohistochemistry (Fig. 1j-1) on sections fixed for three days. The respective distribution pattern of labeled cells was highly similar when comparing mRNA and protein distribution. However, somewhat fewer cells appeared immunopositive than in situ hybridization labeled (Fig. 1).

\section{Procedure}

Paraffin-embedded tissues were cut to $4 \mu \mathrm{m}$ (Microm ERGO Star Rotations-microtome, Microm) and mounted on SuperFrost Plus microscope slides (Menzel). A few older sections with a thickness of $7 \mu \mathrm{m}$ were also included. Sections were dewaxed in xylene overnight at room temper-

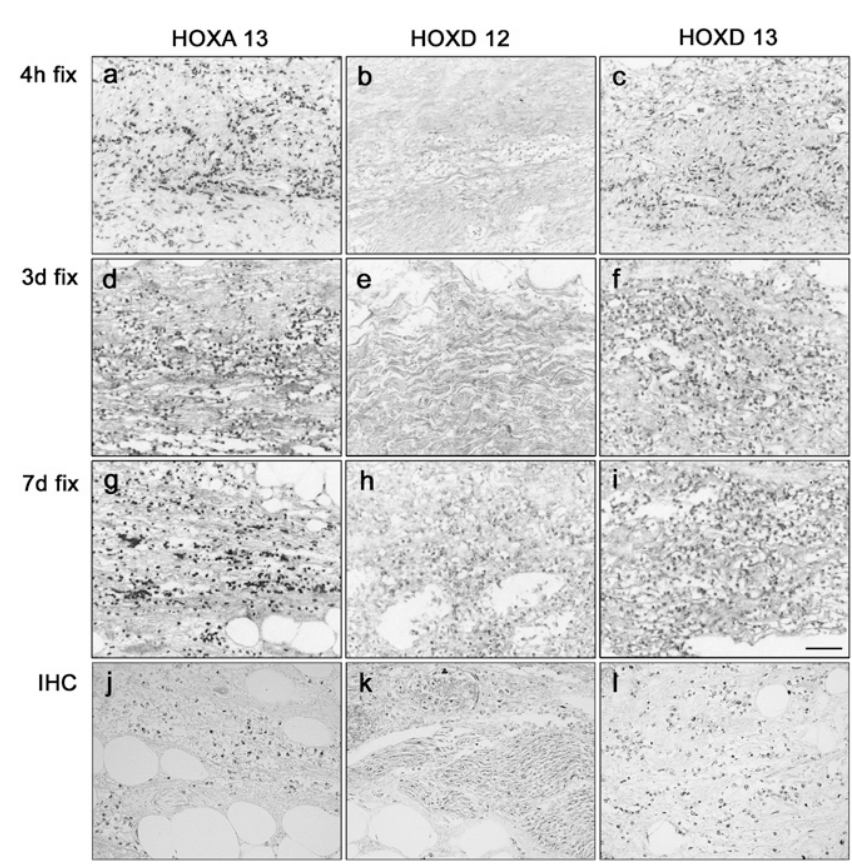

FIGURE 1. Influence of fixation time on mRNA detection: To investigate the influence of fixation time on the detectability of HOX mRNAs, we subjected equal parts of one post-mortem adult rectum specimen to different fixation conditions ( $4 \mathrm{~h}, 3 \mathrm{~d}$, and $7 \mathrm{~d}$ in $4 \%$ paraformaldehyde). Sections of the differently fixed specimens were hybridized with specific probes for $\operatorname{HOXA13}(a, d, g)$, HOXD12 $(b, e, h)$, and HOXD13 $(c, f, i)$ mRNA. Verification of distribution patterns was carried out by immunohistochemistry using specific antibodies $(j-l)$. While staining patterns differed markedly between the three mRNAs, no fixation condition related differences in in situ signal distribution or intensity were observed. Photomicrographs depict the lamina muscularis mucosae. Note the relatively rare HOXD12positive cells compared to HOXA13 and HOXD13. This is consistent with the minimal immunohistochemical labeling for HOXD12 $(k)$, while numerous cells are well labeled for HOXA13 $(j)$ and HOXD13 (l). Scale bar in $i$ for $a-l$ represents $100 \mu \mathrm{m}$.

ature. After rehydration in a descending series of alcohol (95\%, 80\%, 70\%, and 50\%; 5 min each), sections were refixed for $10 \mathrm{~min}$ in $2 \%$ paraformaldehyde in $1 \times$ PBS (phosphate buffered saline; $0.9 \% \mathrm{NaCl} ; 10 \mathrm{mM} \mathrm{Na}$-phosphate buffer at $\mathrm{pH}$ 7.4) at $4^{\circ} \mathrm{C}$. This step increases the stability of the superficial layers of the sections without interfering with mRNA detection. After $3 \times 5$ min washes in $1 \times \mathrm{PBS}$, sections were incubated for $10 \mathrm{~min}$ with $2 \mathrm{M} \mathrm{HCl}$ at $30^{\circ} \mathrm{C}$. After $1 \times 5 \mathrm{~min}$ in $10 \times$ PBS and $2 \times 5$ min washes in $1 \times$ PBS, basic proteins were acetylated with $0.5 \%$ acetic anhydrite in TEA $(0.1 \mathrm{M}$ triethylamine $\mathrm{HCl}$ at $\mathrm{pH}$ 7.2). Subsequently sections were washed $5 \times 5 \mathrm{~min}$ in $1 \times \mathrm{PBS}$ and incubated $\left(30 \mathrm{~min}, 37^{\circ} \mathrm{C}\right)$ with proteinase $\mathrm{K}(50 \mu \mathrm{g} / \mathrm{mL}$ in TES [10 mM EDTA, $10 \mathrm{mM} \mathrm{NaCl}$, and $50 \mathrm{mM}$ Tris- $\mathrm{HCl}$ at pH 8.2]).

Sections were again washed $3 \times 5$ min with $1 \times$ PBS, dehydrated in a series of alcohol $(50 \%, 70 \%, 80 \%$, and $95 \%$; 5 min each), and lipids were removed with chloroform ( $5 \mathrm{~min}$, room temperature) followed by a final alcohol step 
(95\%; $5 \mathrm{~min})$. Subsequently, sections were dried in an upright position for $30 \mathrm{~min}$. Prehybridization was carried out with HybriBuffer (Biognostik $\mathrm{GmbH}$ ) supplemented with Triton X100 $(0.2 \%$ for tissue fixed for $4 \mathrm{~h} ; 0.4 \%$ for specimens fixed for $>4 \mathrm{~h})$ over $3 \mathrm{~h}\left(50^{\circ} \mathrm{C}\right)$. Hybridization was performed with HybriBuffer supplemented with $60 \mathrm{pmol} / \mathrm{mL}$ of the respective probes (see Materials and Methods section) and Triton X100 (0.2\% for tissue fixed for $4 \mathrm{~h} ; 0.4 \%$ for specimens fixed for $>4 \mathrm{~h})$ at $50^{\circ} \mathrm{C}$ for the first $15 \mathrm{~min}$ and $30^{\circ} \mathrm{C}$ afterward for overnight $(18 \mathrm{~h})$ incubation. The total volume of Triton X100 and probes was fixed to $180 \mu \mathrm{L} / \mathrm{mL}$ HybriBuffer. After the incubation, excess HybriBuffer was removed by $2 \times 5 \mathrm{~min}$ washes in $0.5 \times$ SSC at room temperature. Subsequently stringent washes were performed in $0.5 \times \mathrm{SSC}$ at $40^{\circ} \mathrm{C}$ for $30 \mathrm{~min}$. To prepare for immunohistochemical detection of the FAMlabeled hybrids, sections were washed $2 \times 5$ min in $1 \times \mathrm{PBS}$ at room temperature. Unspecific binding was blocked by pretreatment of the sections with $10 \%$ normal goat serum (NGS) in $1 \times$ PBS containing $0.4 \%$ Triton X100 or $0.2 \%$ Triton X100 for lightly fixed tissue for $60 \mathrm{~min}$ at $25^{\circ} \mathrm{C}$. Incubation with a rabbit anti-FITC antibody conjugated to alkaline phosphatase (1:100; A4843; Sigma-Aldrich) was performed in the same buffer supplied with 5\% normal rabbit serum and $10 \%$ NGS overnight at $4^{\circ} \mathrm{C}$. After two washing steps $(1 \times 5 \mathrm{~min}, 1 \times \mathrm{PBS} ; 1 \times 5 \mathrm{~min}$ alkaline phosphatase reaction buffer $[0.1 \mathrm{M}$ Tris, $0.1 \mathrm{M} \mathrm{NaCl}$, and $0.05 \mathrm{M} \mathrm{MgCl}_{2}$ at $\left.\mathrm{pH} 9.5\right]$ ), sections were stained $2 \times 20 \mathrm{~min}$ in NBT/BCIP staining solution (Roche). The staining reaction was terminated by 1 min washing in tap water. Sections were subsequently dehydrated in a series of graded alcohols for 2 min each step. After clearing the sections in xylene $(2 \times$ 2 min), slides were cover slipped with SPURR (Spurr 1969) and incubated for $48 \mathrm{~h}$ at $35^{\circ} \mathrm{C}$ for polymerization.

After optimization of the protocol we compared HOX mRNA staining patterns obtained by our method with two previously published chromogenic protocols (Breitschopf et al. 1992; Blumer et al. 2006) in adult hindgut specimens. The Breitschopf et al. (1992) protocol was slightly modified for the use of FAM-labeled probes. As depicted for HOXD13 mRNA in the upper panel of Figure 2 tissue fixed for $4 \mathrm{~h}$ displayed similar staining patterns with all three techniques in the epithelial layer of adult rectum. However, conservation of tissue integrity was superior in our novel technique (Fig. 2, upper panel). Both formerly published methods displayed marked reduction or total loss of signal in specimens fixed for 3 or $7 \mathrm{~d}$ (not shown), while labeling quality obtained by the improved method was constantly high (Fig. 2c,d). Controls for staining specificity were performed by the addition of 1000-fold excess of non-FAM-labeled oligonucleotide probes (Fig. 2e, depicted for HOXD13) or without the probes. Both resulted in entire loss of signal. Staining obtained for HOX mRNA by in situ hybridization was compared to the distribution of HOX protein by means of immunohisto-

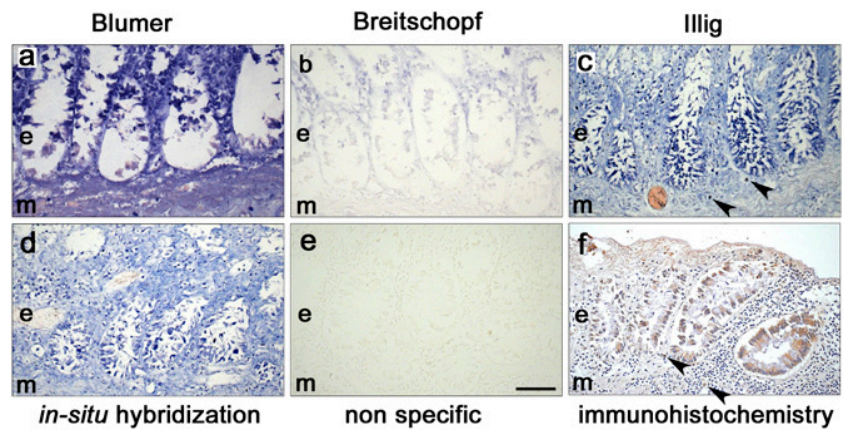

FIGURE 2. Comparability with established protocols and specificity of the improved in situ hybridization protocol: In situ hybridization for HOXD13 mRNA was performed on adult rectum sections using recently published methods. The epithelial layer (e) at the border to the lamina muscularis mucosae $(\mathrm{m})$ is depicted for lightly fixed sections stained according to the methods of Blumer et al. (2006)(a), Breitschopf et al. (1992)(b), and our protocol (c). Although signal intensity varied between methods, the distribution pattern was comparable. Note the high quality labeling in specimens fixed for $7 \mathrm{~d}(d)$ and improved tissue integrity obtained by our protocol. Specificity of labeling was established by comparing normally incubated sections $(c, d)$ with sections hybridized in the presence of a 1000-fold excess of non-FAM-labeled probes $(e)$ and immunohistochemically stained sections using a specific anti-HOXD13 antibody $(f)$. Note the similarity of immunohistochemical and in situ hybridization derived labeling in epithelial and some cells in the lamina muscularis mucosae (arrowheads in $c, f$ ). Scale bar in $e$ (for $a-f$ ) represents $100 \mu \mathrm{m}$.

chemistry on neighboring sections (Fig. 2f, depicted for HOXD13). Cellular distribution patterns were very similar across all methods applied. The fluorescence signal of the FAM labeling was hardly detectable in any sample, supporting the increased sensitivity of the chromogenic detection (data not shown).

To evaluate the potential of our protocol as a diagnostic tool, we selected the intestinal epithelia-specific nuclear transcription factor CDX-2. CDX-2 belongs to the cluster of Para-Hox genes and is strongly up-regulated in adenocarcinoma of gastrointestinal origin. The staining obtained by in situ hybridization (Fig. $3 \mathrm{a}-\mathrm{c}$ ) or by immunohistochemistry (Fig. 3d-f) on sections of colon-carcinoma specimens shows similar patterns of expression. The monoclonal antibody CDX2-88, which was used in our study, was previously evaluated for its specificity and quality as a diagnostic tool (for review, see Li and Folpe 2004).

CDX-2 is expressed for a limited time during embryogenesis in the endoderm of the mid- and hindgut (Beck 2002), however on a much lower level than in carcinoma. Thus, we also investigated CDX-2 expression in embryonic tissue to obtain information on the dynamic range of our novel technique. As expected, patterns and signal intensities varied with embryonic age. This is depicted for CDX-2 mRNA and protein in Figure 4. While no signal was detected in sections obtained from embryos $<7$ wk old (Fig. $4 \mathrm{a}, \mathrm{d})$, high levels of CDX-2 mRNA and protein labeling were observed in endothelial cells of 8 -wk-old embryos 


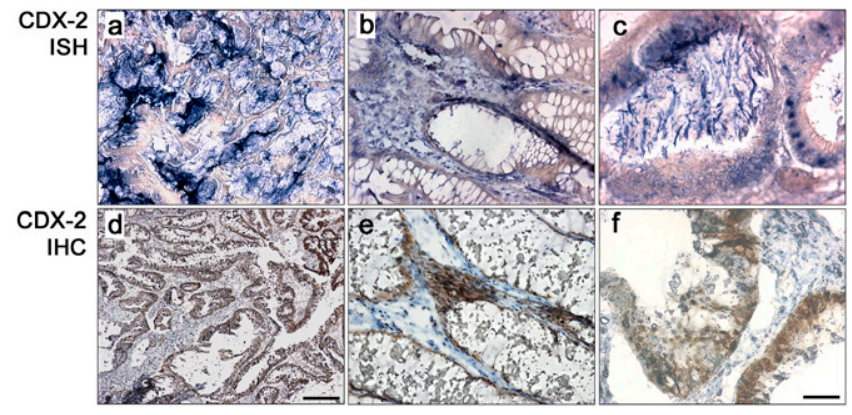

FIGURE 3. Diagnostic usability of the optimized in situ hybridization protocol: To analyze the potentials of our protocol as diagnostic means, we investigated the mRNA and protein distribution of the intestinal tumor marker CDX-2 in tumor tissues. Photomicrographs of colon adenocarcinoma are depicted after in situ hybridization $(a-c)$ or immunohistochemical labeling $(d-f)$ for CDX-2. In situ hybridization (ISH) was done with an alkaline phosphatase conjugated antibody. Reaction with NTB produces a blue signal. Immunohistochemistry (IHC) was carried out using horseradish-peroxidase conjugated antibodies and diaminobenzidine staining, resulting in brown labeling. Sections processed for IHC were Nissl counterstained for better histological identification. Note the matching distribution of CDX-2 mRNA $(a-c)$ and protein $(d-f)$ at both the gross anatomical $(a, d)$ and cellular $(b, e ; c, f)$ level. Scale bar in $d$ (for $a, d$ ) represents 50 $\mu \mathrm{m}$; in $f$ (for $b, c, e, f)$ represents $200 \mu \mathrm{m}$.

(Fig. 4b,e). Later in development, CDX-2 expression faded gradually (Fig. 4c,f, 12-wk-old embryo). This time course was established from a total of 29 embryos fixed for different times and stored for up to $3.5 \mathrm{yr}$. These samples were classified due to their accessibility by two previously published methods (Breitschopf et al. 1992; Blumer et al. 2006). Group I (supposed to be shortly fixed) contains well stainable tissue, group II (supposed to be medium fixed) members displayed faint staining of fewer cells, and specimens of group III (supposed to be long fixed) were not accessible for labeling by these two methods. All specimens with an embryonic age $>8$ wk displayed staining of endothelial cells with our in situ hybridization protocol, irrespective of their classification as group I, II, or III. Immunohistochemical staining of CDX-2 protein with the monoclonal antibody CDX2-88 confirmed the spatial and temporal expression pattern of CDX-2 mRNA, although specimens of group III did not display immunoreactivity.

The initial idea triggering the optimization of our in situ hybridization protocol was to study HOX mRNAs in human embryonic tissues. As shown in Figure 5, we obtained marked staining for all three HOX mRNAs investigated in the hindgut of embryos at developmental ages of 7-10 wk. The labeling followed distinct spatial and temporal patterns for each mRNA. All three genes were expressed in endothelial cells at the embryonal age of 8-10 wk (Fig. 5). HOXA13 and HOXD13 mRNAs were observed also in mesenchymal cells during this period (Fig. 5a,c,d,f,g,i). In contrast, HOXD12 was expressed most prominently during late week eight (Fig. 5e), but considerably less during week
10 (Fig. 5b,h). The same specimens as used for the CDX-2 mRNA expression time course were investigated for the HOX gene expression. With our chromogenic method all specimens displayed labeling of equal quality (Fig. 5), irrespective of fixation conditions.

We are aware that most FFPE sections stored in tissue collections are $>3.5 \mathrm{yr}$, which is the maximum storage time of the embryonic tissues used for our investigation of $H O X$ gene expression. RNA stability and detectability after long storage periods were demonstrated previously in cancer tissue (Capodieci et al. 2005). However, this may not apply for mRNA present only in low amounts. Therefore, we investigated the expression of HOX genes in human embryonic tissue samples stored over longer periods. Five embryonic specimens were studied, which were embedded in paraffin immediately after fixation and stored for 12-17 $\mathrm{yr}$ in the dark at room temperature. All these specimens displayed distinct signals for HOXA13, HOXD12, HOXD13, and CDX-2 mRNAs (Fig. 6, depicted for specimens stored for $17 \mathrm{yr}$ ). There was no obvious difference whether tissues were stored as entire blocks or sections. Although no hindgut sections were available, considerable expression of all four mRNAs was observed in other organs. Labeling of cartilage cells was very similar for HOXD12 and HOXD13 mRNAs (Fig. 6a,b); both were also detected in the perichondrium of the distal phalanxes of the upper limbs (Fig. 6c,d) at the beginning of the eighth developmental week. HOXA13 was markedly expressed in the duct system of the pancreas at the end of developmental week eight (Fig. 6e), while CDX-2 mRNA (Fig. 6f) was restricted to a few cells in the pancreatic parenchyma at the same age.

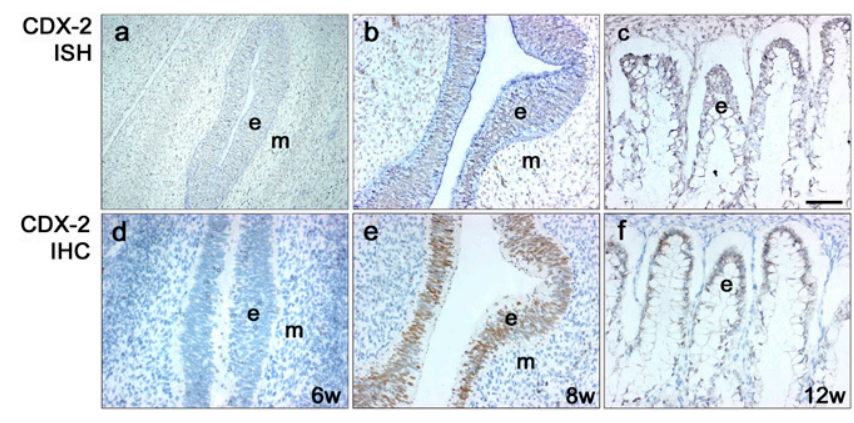

FIGURE 4. Sensitivity of the optimized in situ hybridization protocol: During embryogenesis CDX-2 protein is detectable from week 8 and declines until birth. We used the relatively low expression of CDX-2 during ontogeny to evaluate the sensitivity of our in situ hybridization protocol. Embryonic tissues of six $(a, d)$, eight $(b, e)$, and $12(c, f)$ weeks of age are depicted after in situ hybridization $(a-c$; ISH) or immunohistochemistry $(d-f ;$ IHC). No labeling was obtained by in situ hybridization $(a)$ or immunohistochemistry $(d)$ at the age of six weeks. In line with its known temporal expression, prominent CDX-2 specific staining was observed by both methods in tissues obtained from 8-wk-old embryos $(b, e)$. Four weeks later in development $(c, f)$ labeling was markedly reduced, but still present in some epithelial cells. Scale bar in $c$ for $a-f$ represents $100 \mu \mathrm{m}$. 


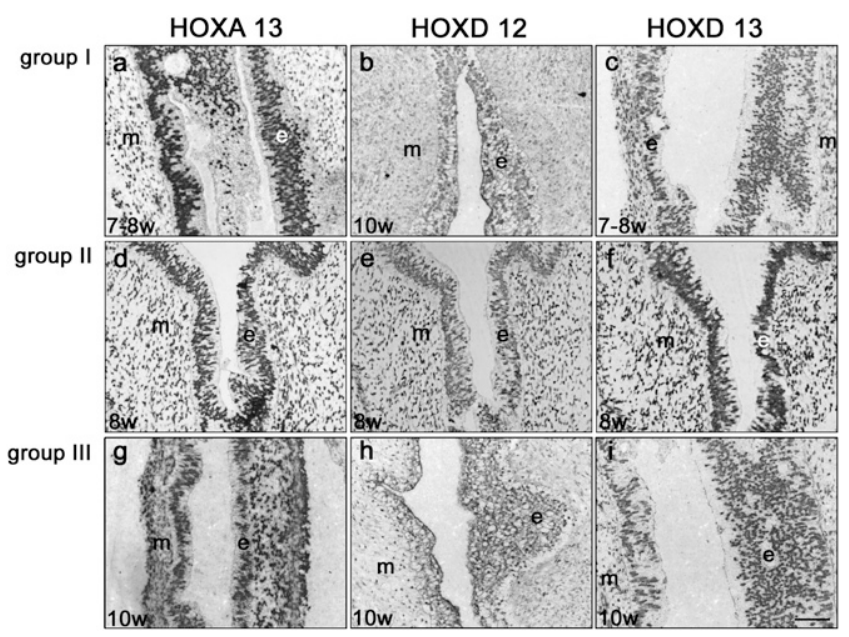

FIGURE 5. HOX mRNA detection in differently fixed embryonic tissues: Short-term stored (maximum $3.5 \mathrm{yr}$ ) archival embryonic tissues were categorized according to their accessibility to staining by conventional techniques into three groups. Group I, moderate to intense staining (short-term fixed); group II, pale to faint staining (midterm fixed); and group III, no labeling (long-term fixed). Photomicrographs depict group I $(a-c)$, group II $(d-f)$, and group III $(g-i)$ classified embryonic tissue of different embryonic stages $(\sim 7-8$ wk in $a, c-f ; \sim 10 \mathrm{wk}$ in $b, g-i)$ processed by our protocol. Sections were hybridized for HOXA13 $(a, d, g)$, HOXD12 $(b, e, h)$, and HOXD13 $(c, f, i)$ mRNA. Labeling of epithelial cells was observed for all probes at the embryonic ages depicted. In contrast, mesenchymal cells display strong labeling over this time period only for HOXA13 and HOXD13 mRNAs, while HOXD12 mRNA expression appeared markedly reduced in 10-wk-old embryos $(b, h)$. Note the morphological changes in the epithelial cells, indicative of embryonic age. Scale bar in $i$ for $a-i$ represents $100 \mu \mathrm{m}$. e, epithelial layer; m, mesenchymal layer.

In addition we had the opportunity to investigate an entire human embryo specimen (Fig. 7e), which had been on display in an anatomical collection, conserved in formalin since 1989 without cooling or replacement of formalin. After embedding in paraffin, we were able to obtain specific staining for all three HOX mRNAs investigated, however in a very little number of cells. HOXA13-positive cells were observed in the stomach (Fig. 7a) and kidney. HOXD12 mRNA was detected in the urethra, kidney (Fig. $7 \mathrm{~b}$ ), and perichondrium of the proximal phalanxes of the limbs (Fig. 7d). HOXD13 mRNA was expressed in the hindgut (Fig. 7c) and the distal phalanxes of the limbs.

\section{DISCUSSION}

In situ hybridization is a highly valuable research and diagnostic tool used either on its own or in combination with immunohistochemistry. Since the sequencing of entire genomes, it is relatively easy, fast, and inexpensive to design and synthesize antisense probes for any kind of mRNA. Unfortunately, in situ hybridization is highly dependent on the accessibility of the target mRNA and permeability of the cell membranes. Therefore, the lack of standard procedures for tissue fixation in clinical and anatomical institutions is the main drawback for accurate gene-expression analysis by in situ hybridization. We now developed and evaluated an in situ hybridization protocol, which allows the analysis of mRNA distribution patterns in specimens obtained from anatomical and pathological archives.

\section{Methodological considerations}

In most anatomy, histology, embryology, and pathology departments neither the concentration of fixative (mostly, $3 \%-10 \%$ paraformaldehyde) nor fixation time is standardized. Thus, target retrieval procedures are crucial to allow successful in situ hybridization in fixed tissue. To improve the target retrieval we compared sections obtained after three different fixation protocols, covering short-term fixation ( $4 \mathrm{~h}, 4 \%$ paraformaldehyde), medium fixation ( $3 \mathrm{~d}$, $4 \%$ paraformaldehyde), and long fixation ( $7 \mathrm{~d}, 4 \%$ paraformaldehyde). The two latter fixations demark the most common fixation time frame used in our Department and resulted in loss of staining applying two previously published methods (Breitschopf et al. 1992; Blumer et al. 2006). Consequently, these samples are representative for the collection. Target retrieval, conservation of tissue integrity, and probe permeation into the sections were improved in several steps. Due to space limitations it was not feasible to

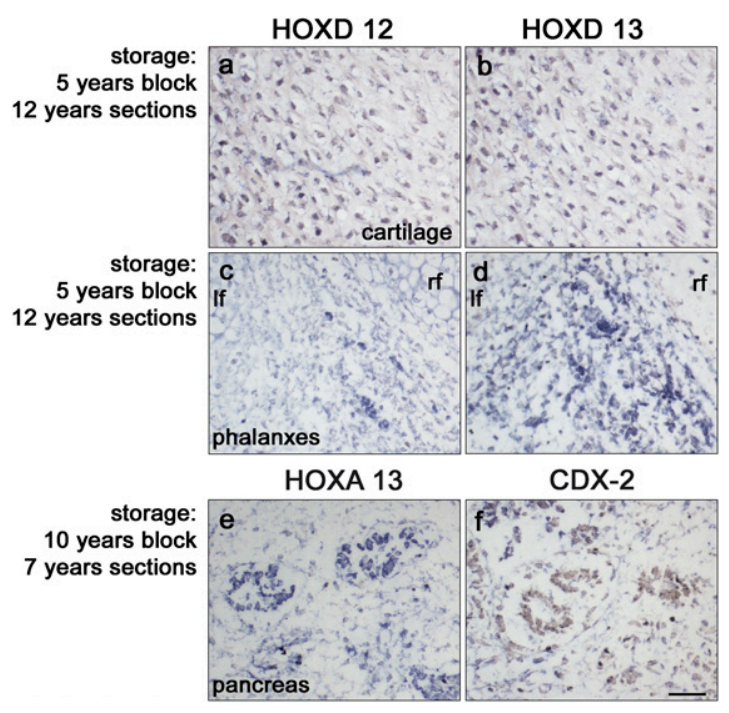

FIGURE 6. Applicability of the improved in situ hybridization protocol in long-term stored paraffin-embedded specimens: In situ hybridization labeling is depicted for $\operatorname{HOXD} 12(a, c), \operatorname{HOXD} 13(b, d)$, HOXA13 $(e)$, and CDX-2 $(f)$ mRNA on $4-\mu \mathrm{m}$ sections obtained from embryos (anatomical age from early to late eighth embryonic week) stored for $17 \mathrm{yr}$. Marked labeling of HOXD12 and HOXD13 mRNA was detectable in cartilage cells $(a, b)$ and in groups of cells in the distal phalanxes $(c, d)$. HOXA13-positive cells were observed in the duct system of the pancreas $(e)$. In contrast, CDX-2 expression was restricted to a few positive cells in the pancreatic parenchyma $(f)$. Scale bar in $f$ for $a-f$ represents $100 \mu \mathrm{m}$. lf, little finger; rf, ring finger. 


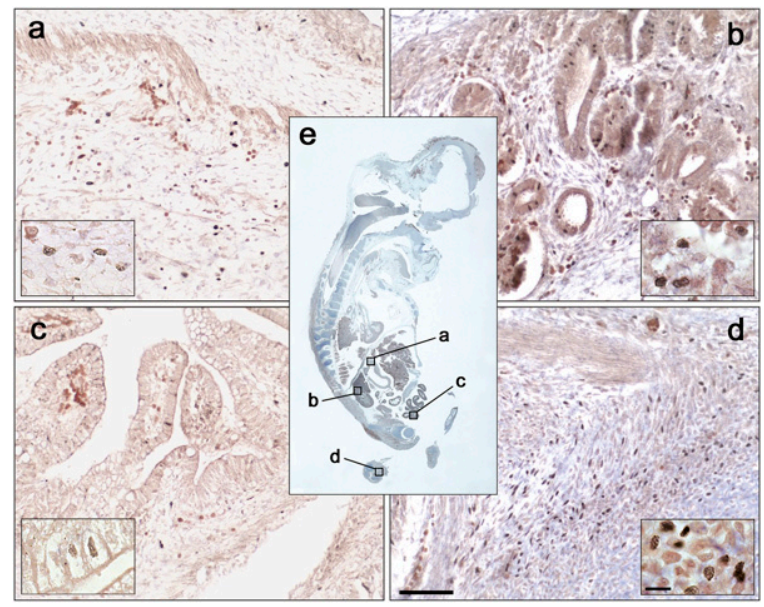

FIGURE 7. Applicability of our in situ hybridization protocol in long-term formalin stored specimens: In situ hybridization labeling is depicted for HOXA13 $(a)$, HOXD12 $(b, d)$, and HOXD13 (c) mRNA on $4-\mu \mathrm{m}$ sections obtained from an embryo (overview in $e$, anatomical age about 11th fetal week) stored for $19 \mathrm{yr}$ in formalin. The number of labeled cells is markedly less than in long-term stored FFPE specimens, however the remaining staining is specific, underlining the ruggedness of our technique regarding fixation and storage conditions. Photomicrographs depict HOXA13-expressing cells in the stomach $(a)$, HOX D12-positive cells in the kidney $(b)$, and perichondrium of the proximal phalanxes of the lower limb $(d)$ and HOXD13-labeled cells in the hindgut. Scale bar in $d$ for $a-d$ represents $100 \mu \mathrm{m}$, scale bar in higher magnification insert of $d$ for all inserts represents $10 \mu \mathrm{m}$. Squares in $e$ indicate the area depicted in the respective images.

present all these data in detail. However, for easier follow up, the tested conditions are discussed below.

\section{Target retrieval and conservation of tissue integrity}

Overnight deparaffinization with xylene provided somewhat better target accessibility than the standard protocol of $3 \times 5$ min xylene. A superficial refixation with $2 \%$ PFA at $4^{\circ} \mathrm{C}$ after dewaxing is essential for the improved tissue conservation in our protocol and does not interfere with antigen accessibility. For target retrieval we tested citrate buffer $(0.1 \mathrm{M}$ at $\mathrm{pH} 5.5 ; 5$ or $10 \mathrm{~min}$ heating in a $400-\mathrm{W}$ microwave oven), $\mathrm{HCl}(0.2,1,2$, and $4 \mathrm{M}$; 5 or $10 \mathrm{~min}$; RT; 30,40 , and $\left.50^{\circ} \mathrm{C}\right)$, and proteinase $\mathrm{K}(10,20,50,80,100$, and $500 \mu \mathrm{g} / \mathrm{mL} ; 15,20$, or $30 \mathrm{~min} ; 37^{\circ} \mathrm{C}$ ) digestions. A 5-10-min microwave treatment in citrate was sufficient to retrieve signal from lightly fixed tissue (4 h PFA, group I) but was insufficient for samples fixed for a longer time. In addition, this treatment markedly reduced tissue integrity. The treatment with low concentrations of $\mathrm{HCl}$ had similar unmasking properties as citrate buffer, but better conservation of the histological structures. The highest $\mathrm{HCl}$ concentration (4 M), as well as $2 \mathrm{M}$ at higher temperatures, led to severe damage in tissues fixed for $4 \mathrm{~h}$ or assigned to group I. The best results for all types of tissues were obtained by a 10 -min treatment with $2 \mathrm{M} \mathrm{HCl}$ in $1 \times \mathrm{PBS}$ at $30^{\circ} \mathrm{C}$. Proteinase $\mathrm{K}$ concentrations $<50 \mu \mathrm{g} / \mathrm{mL}$ enabled well detectable staining in lightly fixed tissue ( $4 \mathrm{~h} \mathrm{PFA}$, group I), but not in tissues fixed for $>4 \mathrm{~h}$. Concentrations of $100 \mu \mathrm{g}$ proteinase $\mathrm{K} / \mathrm{mL}$ and more caused marked histological damage in specimens of all fixation groups. Moderate concentrations of $50 \mu \mathrm{g}$ proteinase $\mathrm{K} / \mathrm{mL}$ applied for $30 \mathrm{~min}$ at $37^{\circ} \mathrm{C}$ in combination with $2 \mathrm{M} \mathrm{HCl}$ treatment at $30^{\circ} \mathrm{C}$ produced reliable and constant target retrieval for all differentially fixed specimens (i.e., adult rectum samples fixed under controlled conditions and archival embryonic tissues).

\section{Preincubation and incubation}

Prehybridization and hybridization were performed using a commercial HybriBuffer (Biognostik). The addition of Triton X100 was tested for improvement of probe penetration into the tissue. Triton X100 concentrations of $0.1 \%$ did not improve results, $0.2 \%$ was ideal for tissue fixed for $4 \mathrm{~h}$ and group I, while $0.4 \%$ was necessary to enhance the penetration in strongly fixed tissue ( 3 or $7 \mathrm{~d}$; groups II and III). On the other hand, $0.4 \%$ Triton X100 induced structural damage to sections of lightly fixed tissue. Therefore we recommend different concentrations of Triton X100. No obvious difference in staining pattern or efficiency was detected between 4 - and $7-\mu \mathrm{m}$-thick sections, suggesting sufficient permeability of the sections.

Stringent wash conditions were modified through adjustment of salt concentrations. At 1 and $2 \times$ SSC, unspecific background staining remained on some sections. At $0.5 \times$ SSC, the labeling intensity of specifically stained cells was indistinguishable from that of higher salt washes, but the background staining was markedly lower. The addition of Triton X100 $(0.1 \%$ to $0.4 \%)$ did not further reduce background staining but damaged lightly fixed sections at higher concentrations.

\section{Probe detection}

Direct evaluation of the fluorescence signal of the FAMlabeled probes (up to four oligos/mRNA) proved as not sensitive enough using standard fluorescence microscopy. This is in line with the findings of a previous study targeting nascent RNA in the nucleus of cancer cells (Capodieci et al. 2005). In addition, the interpretation of weak fluorescence signals hybridized to mRNA in the cytosol is problematic, as strongly fixed tissue displays marked auto-fluorescence, which may be reduced (i.e., by 50\%) (Capodieci et al. 2005), but not eliminated. Therefore, we applied an enzyme linked chromogenic technique. Detection of the FAM-labeled oligonucleotides was carried out with an anti-FITC antibody, because no specific antiFAM antibodies are commercially available. However, cross-reactivity is high, as FAM and FITC differ only by a single carboxyl group. The combination of the Sigma antibody with the Roche NBT/BCIP staining solution 
yielded better results than detection kits available from Vector or Dako, mainly due to less background staining. Alkaline phosphatase was preferred over horseradish-peroxidase to avoid the staining of erythrocytes containing high amounts of residual peroxidases.

\section{Specificity and reproducibility}

Results obtained by our protocol applied on the tissue used for the development of the technique and some other adult tissues taken from the collection of the department were highly comparable between different tissues. No differences in staining intensity or background labeling were evident, suggesting reliable target retrieval and conservation of tissue integrity. Labeling was entirely blocked by omission of FAM-labeled probes and by addition of a 1000-fold excess of unlabeled DNA oligonucleotides. This proves that hybridization conditions did not allow unspecific binding and that the immunohistochemical detection is disturbed neither by cross-reactivity of the antibody nor by endogenous enzyme activities. The HOX mRNA distributions investigated in this study represent novel findings. Therefore, staining specificity was controlled by comparison of in situ signal distribution to immunohistochemical labeling patterns of the respective HOX proteins. Albeit identical staining patterns were observed, somewhat fewer cells were immunohistochemically labeled in group II specimens compared to group I tissues. Potentially partial blockade of antigens due to strong fixation is supported by the complete lack of immunoreactive cells in group III (longterm fixed) tissue. In adult tissue both in situ hybridization and immunohistochemistry yielded only faint to moderate labeling of HOX mRNAs and proteins, respectively.

\section{Comparability and applicability}

Staining patterns obtained with our protocol are comparable to those obtained by conventional techniques in group I tissues. However, the optimized protocol described here is superior to other chromogenic protocols (Breitschopf et al. 1992; Blumer et al. 2006) in most types of tissues. Besides producing reliable in situ hybridization staining in tissue irrespective of fixation conditions, tissue integrity was very well conserved.

Samples of six additional embryos were studied to investigate the influence of long-term storage on mRNA detection. Five of these embryos were embedded immediately after fixation in paraffin and stored for up to $17 \mathrm{yr}$. There was no obvious difference between tissue stored as an entire block and cut immediately before the experiment and those kept for several years as a block and subsequently additional years as sections. In contrast, the specimen stored for $19 \mathrm{yr}$ in paraformaldehyde displayed a markedly reduced number of labeled cells. However, the distribution of labeled cells was distinct for all three mRNAs investigated and highly comparable to tissue stored for short term. Thus, specimens stored for long term are suitable for scientific investigations if kept as FFPE material, while their scientific value appears reduced by storage in paraformaldehyde.

\section{Application as a diagnostic and scientific tool}

The extremely strong labeling of CDX-2 mRNA, which fits very well to the strong immunoreactivity of CDX-2 protein in colon carcinoma, expands the usability of our novel technique also to diagnostic applications. Of note is the fact that light in situ hybridization staining was observed within the transition zone from tumor to healthy tissue, while this area was devoid of staining in immunohistochemistry. This may be caused by higher sensitivity of the in situ hybridization protocol than immunohistochemistry as applied here. However, this pale to moderate signal may also demark cells which already express some CDX-2 mRNA but do not contain detectable levels of CDX-2 protein. The latter may be diagnostically important to judge whether tumor tissue was completely resected or not. Only faint staining of endothelial cells was observed in healthy tissue, proving the specificity of labeling. CDX-2 was also used as reference to show specificity and sensitivity of our protocol on embryonic tissue. The temporal limitation of CDX-2 expression during ontogeny made it an ideal candidate for this task. The embryonic specimens within our collection cover the ages of 6-12 wk; CDX-2 is not expressed up to week 7, thereafter its expression rises quickly, with maximum expression at $\sim 8-10$ wk of age and subsequent gradual reduction of mRNA levels. All our specimens fit nicely into this proposed scheme, irrespective of their group I to III classifications.

The expression of HOX genes has not been established in human tissue so far. Examination of animal models showed expression of Hoxa 13 in the early developmental stage of the gastro-enteric and urogenital tracts in mouse and chicken (Yokouchi et al. 1995; de Santa Barbara and Roberts 2002). Hoxd12 expression was reported in the extremities and the gastro-enteric and urogenital tract in mouse and chicken embryos (Kondo et al. 1996; Zakany et al. 1996; de Santa Barbara and Roberts 2002). Hoxd13 mRNA was observed during the development of the extremities and in the developing "hindgut" of the chicken and mouse (Dolle et al. 1993b; Roberts et al. 1995; Kondo et al. 1996; Roberts et al. 1998; de Santa Barbara and Roberts 2002). Our results show differential expression of HOXA13, HOXD12, and HOXD13 mRNAs in human embryos/fetuses, suggesting high importance of $H O X$ genes also in human development. The expression of HOXA13, HOXD12, and HOXD13 mRNAs in human embryonic tissue is widely in line with the expression patterns proposed from animal models. Thus, HOXA13 expression was observed from embryonic weeks 6-11; HOXD13 mRNA was observed beginning in developmental week 7 and persisting over late week 12 (the most developed stage investigated). However, differences in temporal expression of the $H O X$ genes investigated were 
also observed. Likewise, HOXD12 mRNA appeared less highly expressed than expected from chicken and mouse (Dolle et al. 1993b; Roberts et al. 1995; Kondo et al. 1996; Roberts et al. 1998; de Santa Barbara and Roberts 2002) and was observed only from late week 8 to week 11. A total of 29 embryos were investigated. Only three of them were fixed under defined conditions regarding paraformaldehyde concentration and incubation time. All others were fixed from several hours to several days, even weeks, before embedding and sectioning. Irrespective of these discrepancies, sections from all embryos yielded distinct staining patterns for all four probes investigated (HOXA13, HOXD12, HOXD13, and CDX-2). Differentially fixed embryos of the same developmental age displayed highly similar staining patterns.

\section{Conclusions}

Our optimized protocol provides a highly sensitive tool to study mRNA expression on tissues that were processed for immunohistochemistry or histology. This protocol enables the investigation of archival tissues collected through at least the last two decades in a broad range, focusing on detection of mRNAs on low expression limits without the need of highly sophisticated microscopy equipment. In addition, critical specimens can be investigated easily by two independent methods. Combination of in situ hybridization and immunohistochemistry, which target mRNA and protein, respectively, yields higher confidence in data than one method alone. In addition, through this combination, the developmental onset and duration of mRNA expression and protein presence can be defined much more precisely.

\section{MATERIALS AND METHODS}

\section{Tissue}

A total of 741 sections were included in this study. All the embryonic and adult samples belong to the collection of the Division of Clinical and Functional Anatomy (Department of Anatomy, Histology and Embryology, Innsbruck Medical University). Sampling of embryonic and adult specimens was done in accordance with Austrian laws, including parental or patient consent, respectively.

Newly sampled specimens were fixed in $4 \%$ paraformaldehyde (PFA) in $1 \times$ PBS, while specimens taken from the collection were fixed in different formaldehyde solutions (3\%-7\%; also termed formalin) and embedded in paraffin in a routine histological infiltration processor (Miles Scientific Inc.). Freshly collected samples were fixed for $4 \mathrm{~h}$; existing tissue samples taken from the collection were mostly stored for a longer period in formalin (up to $19 \mathrm{yr}$ in a single case) prior to paraffin embedding.

\section{In situ hybridization}

Probe design: Single-stranded antisense DNA oligomer probes were designed using the following rules: 45 bases in length, 22-23 $\mathrm{G}$ or $\mathrm{C}$, no more than three $\mathrm{G}$ or $\mathrm{C}$ in a row, no hairpins stabilized by more than three bases, and no dimerization of probes with more than four bases. Two to four probes with a distance of at least 100 bases along the mRNA sequence (to minimize steric hindrance) were used per target mRNA. The specificity of probes was checked by BLAST search. Probes were synthesized on an automated system and $3^{\prime}$ and 5' FAM-labeled and PAGE-purified (Microsynth). Unlabeled probes were used in displacement experiments as controls.

Probes and sequences used in this study (end numbers indicate position on mRNA) are as follows:

CDX2-705: 5'-ACCACTCGATATTTGTCTTTCGTCCTGGTTTT CACTTGGCTGCCG-3';

CDX2-1241: 5'-CCCAAATCCCACTTGTCTTACTCCTGGCTCC CATTTTTCCTCTGA-3';

CDX2-1588: 5'-GCTTTCTATCTTAGCTGCCTTTGGCTTCCGC AGTGTAAACCTTGC-3';

HOXA13-986: 5'-AATTGCACCTTGGTATAAGGCACGCGCTT СТTТСТСССССТССТА-3';

HOXA13-1420: ATTTTGGGGGTTGACGTTTGACATTTAACGG GCTGGGCTGATGGG-3';

HOXA13-1613: 5'-AGATTTACCTGAGCAGACGCTTAACATGC AAAGGGAATGGCGACC-3';

HOXD12-37: 5'-AAAATCCATTATTGGGCTACCTTGGGCTCT CCGCAGTAGCCGAGC- $3^{\prime}$;

HOXD12-767: 5' -ATTCGTTCTCCAACTCCGCAATCTGCTGCT TCGTGTAGGGTTTCC-3';

HOXD12-891: 5'-AGCACCACGCGCTTCTTCTTCATACGCCT GTTCTGGAACCAGATT-3';

HOXD13-879: 5' -TTCTTCCTCCCTCTTCGGTAGACGCACATG TCCGGCTGATTTAGA-3';

HOXD13-981: 5'-GTAGCAGCCGAGATACGCCGCCGCTTGTC CTTGTTAATGAATTTG-3';

HOXD13-1091: 5'-GCCAACCTGGACCACATCAGGAGACAGT ATCTTTGAGCTTGGAGA-3'; and

HOXD13-1266: 5' -CAGAACTACAAAGTCAGGTTGGGCAGCA GAAGGTTTTAGAGCCAG-3'.

Immunohistochemistry

Immunohistochemistry was performed using standard techniques (Blumer et al. 2006). For the detection of human HOXD13, a rabbit polyclonal antiserum (Abcam ab19866) was used at a dilution of 1:100. Horseradish-peroxidase conjugated goat-anti-rabbit (DakoCytomation P 0448) secondary antibody was applied at 1:1000 dilution.

\section{Morphological analysis}

The sections were microscopically examined under a Zeiss Axiophot microscope (Zeiss), equipped with a Zeiss AxioCam HR camera. Digital photomicrographs were processed with the AxioVision V 4.1 (Zeiss) software.

\section{ACKNOWLEDGMENTS}

This work was supported by the Austrian Science Fund grants P18471-B5 and P20107-B5. We thank Dr. Hans Joachim Wolf and Dr. Felix Aigner for constant support of our tissue collection. No financial interests other than those stated above exist.

Received July 18, 2008; accepted May 13, 2009. 


\section{REFERENCES}

Beck F. 2002. Homeobox genes in gut development. Gut 51: 450454.

Blumer MJ, Schwarzer C, Perez MT, Konakci KZ, Fritsch H. 2006. Identification and location of bone-forming cells within cartilage canals on their course into the secondary ossification centre. J Anat 208: 695-707.

Breitschopf H, Suchanek G, Gould RM, Colman DR, Lassmann H. 1992. In situ hybridization with digoxigenin-labeled probes: Sensitive and reliable detection method applied to myelinating rat brain. Acta Neuropathol 84: 581-587.

Capodieci P, Donovan M, Buchinsky H, Jeffers Y, Cordon-Cardo C, Gerald W, Edelson J, Shenoy SM, Singer RH. 2005. Gene expression profiling in single cells within tissue. Nat Methods 2: 663-665.

de Santa Barbara P, Roberts DJ. 2002. Tail gut endoderm and gut/ genitourinary/tail development: A new tissue-specific role for Hoxa13. Development 129: 551-561.

Dolle P, Dierich A, LeMeur M, Schimmang T, Schuhbaur B, Chambon P, Duboule D. 1993a. Disruption of the Hoxd-13 gene induces localized heterochrony leading to mice with neotenic limbs. Cell 75: 431-441.

Dolle P, Izpisua-Belmonte JC, Brown J, Tickle C, Duboule D. 1993b. Hox genes and the morphogenesis of the vertebrate limb. Prog Clin Biol Res 383A: 11-20.

Duboule D. 1994. How to make a limb? Science 266: 575-576.

Gehring WJ. 1987. Homeoboxes in the study of development. Science 236: 1245-1252.

Grier DG, Thompson A, Kwasniewska A, McGonigle GJ, Halliday HL, Lappin TR. 2005. The pathophysiology of HOX genes and their role in cancer. J Pathol 205: 154-171.

Johnson F. 1914. The development of the rectum in the human embryo. Am J Anat 16: 1-57.

Kluth D, Hillen M, Lambrecht W. 1995. The principles of normal and abnormal hindgut development. J Pediatr Surg 30: 1143-1147.

Kondo T, Dolle P, Zakany J, Duboule D. 1996. Function of posterior HoxD genes in the morphogenesis of the anal sphincter. Development 122: 2651-2659.
Krumlauf R. 1994. Hox genes in vertebrate development. Cell 78: 191-201.

Lewis EB. 1978. A gene complex controlling segmentation in Drosophila. Nature 276: 565-570.

Li MK, Folpe AL. 2004. CDX-2, a new marker for adenocarcinoma of gastrointestinal origin. Adv Anat Pathol 11: 101-105.

Mark M, Rijli FM, Chambon P. 1997. Homeobox genes in embryogenesis and pathogenesis. Pediatr Res 42: 421-429.

Roberts DJ, Johnson RL, Burke AC, Nelson CE, Morgan BA, Tabin C. 1995. Sonic hedgehog is an endodermal signal inducing Bmp-4 and Hox genes during induction and regionalization of the chick hindgut. Development 121: 3163-3174.

Roberts DJ, Smith DM, Goff DJ, Tabin CJ. 1998. Epithelial-mesenchymal signaling during the regionalization of the chick gut. Development 125: 2791-2801.

Samuel S, Naora H. 2005. Homeobox gene expression in cancer: Insights from developmental regulation and deregulation. Eur J Cancer 41: 2428-2437.

Spurr AR. 1969. A low-viscosity epoxy resin embedding medium for electron microscopy. J Ultrastruct Res 26: 31-43.

Warot X, Fromental-Ramain C, Fraulob V, Chambon P, Dolle P. 1997. Gene dosage-dependent effects of the Hoxa-13and Hoxd-13 mutations on morphogenesis of the terminal parts of the digestive and urogenital tracts. Development 124: 4781-4791.

Yahagi N, Kosaki R, Ito T, Mitsuhashi T, Shimada H, Tomita M, Takahashi T, Kosaki K. 2004. Position-specific expression of Hox genes along the gastrointestinal tract. Congenit Anom (Kyoto) 44: $18-26$.

Yokouchi Y, Nakazato S, Yamamoto M, Goto Y, Kameda T, Iba H, Kuroiwa A. 1995. Misexpression of Hoxa-13 induces cartilage homeotic transformation and changes cell adhesiveness in chick limb buds. Genes \& Dev 9: 2509-2522.

Zakany J, Gerard M, Favier B, Potter SS, Duboule D. 1996. Functional equivalence and rescue among group 11 Hox gene products in vertebral patterning. Dev Biol 176: 325-328.

Zakany J, Fromental-Ramain C, Warot X, Duboule D. 1997. Regulation of number and size of digits by posterior Hox genes: A dosedependent mechanism with potential evolutionary implications. Proc Natl Acad Sci 94: 13695-13700. 

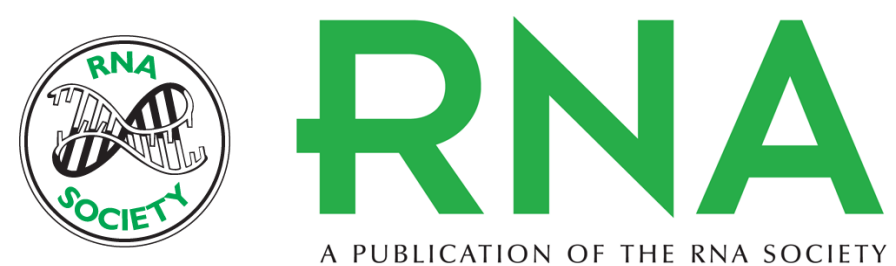

A PUBLICATION OF THE RNA SOCIETY

\section{Breaking the seals: Efficient mRNA detection from human archival paraffin-embedded tissue}

Romana Illig, Helga Fritsch and Christoph Schwarzer

RNA 2009 15: 1588-1596 originally published online June 23, 2009

Access the most recent version at doi:10.1261/rna.1278109

$\begin{array}{ll}\text { References } & \begin{array}{l}\text { This article cites } 26 \text { articles, } 10 \text { of which can be accessed free at: } \\ \text { http://rnajournal.cshlp.org/content/15/8/1588.full.html\#ref-list-1 }\end{array}\end{array}$

License

Email Alerting Receive free email alerts when new articles cite this article - sign up in the box at the Service top right corner of the article or click here.

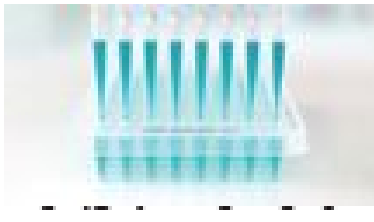

Providing Precise Solutions for your research.

To subscribe to RNA go to:

http://rnajournal.cshlp.org/subscriptions 